\title{
Síndrome antifosfolipídico obstétrico
}

\author{
Obstetric antiphospholipid syndrome \\ Síndrome antifosfolípide obstétrica
}

Daniel Leal Resumen: El síndrome antifosfolipídico obstétrico puede ser causa de importante morbilidad

ORCID: 0000-0002-3924-8607

Hematólogo. Internista. Ex Asistente

Cátedra Hematología. Hospital de

Clínicas. UdelaR

Valentina Zubiaurre

ORCID: 0000-0002-9490-577X

Internista. Profesor Adjunto Clínica

Médica B. Hospital de Clínicas.

UdelaR.

\section{Alvaro Danza}

ORCID: 0000-0001-9070-2230

Internista. Profesor Agregado Clínica Médica 2. Hospital Pasteur. UdelaR.

Mariana Stevenazzi

ORCID: 0000-0002-7652-6610

Hematólogo. Internista. Profesor

Agregado Cátedra Hematología

Hospital de Clínicas. UdelaR.

materno-fetal. Los criterios diagnósticos se definen en 1999 (criterios de Sapporo) que son revisados en 2006 (Sydney), basados en criterios clínicos y de laboratorio. En el 2006 la sociedad internacional de hemostasis y trombosis propone los criterios que definen las morbilidades del embarazo vinculadas al mismo (pérdida fetal tardía, pérdida recurrente del embarazo, parto pretérmino, enfermedad tromboembólica). El objetivo terapéutico es prevenir complicaciones materno-fetal (trombosis maternas y prevenir complicaciones obstétricas). El tratamiento siempre debe ser individualizado según cada caso particular. Se realiza una revisión sobre las distintas situaciones posibles, finalizando con recomendaciones para el mismo.

Palabras clave: síndrome antifosfolipídico, obstétrico, anticuerpos antifosfolipídicos.

Abstract: Obstetric antiphospholipid syndrome can be the cause of significant maternalfetal morbidity. Diagnostic criteria are defined in 1999 (Sapporo criteria) which are revised in 2006 (Sydney), based on clinical and laboratory criteria. In 2006, the International Society of Haemostasis and Thrombosis proposed the criteria that define the morbidities of pregnancy related to it (late fetal loss, recurrent pregnancy loss, preterm delivery, thromboembolic disease). The therapeutic objective is to prevent maternal-fetal complications (maternal thrombosis and prevent obstetric complications). Treatment must always be individualized according to each particular case. A review is carried out on the different possible situations, ending with recommendations for the same.

Key words: antiphospholipid syndrome, obstetric, antiphospholipid antibodies.

Resumo: A síndrome antifosfolipídica obstétrica pode ser a causa de morbidade maternofetal significativa. Os critérios diagnósticos são definidos em 1999 (critérios de Sapporo) que são revisados em 2006 (Sydney), com base em critérios clínicos e laboratoriais. Em 2006, a Sociedade Internacional de Hemostasia e Trombose propôs os critérios que definem as morbidades da gravidez a ela relacionadas (perda fetal tardia, perda recorrente da gravidez, parto prematuro, doença tromboembólica). O objetivo terapêutico é prevenir complicações materno-fetais (trombose materna e prevenir complicações obstétricas). $O$ tratamento deve ser sempre individualizado de acordo com cada caso particular. É feita uma revisão sobre as diferentes situações possíveis, terminando com recomendações para o mesmo.

Palavras-chave: síndrome antifosfolipídeo, obstétrico, anticorpos antifosfolipídeo. 
El Síndrome Antifosfolipídico (SAF), descrito por Hughes, Harris y Gharavi en 1986 es la trombofilia adquirida más frecuente ${ }^{1}$. Puede ser primario (idiopático) o secundario (en el $95 \%$ de los casos a Lupus Eritematoso Sistémico (LES)).

El Síndrome antifosfolipídico obstétrico puede ser causa de importante morbilidad al binomio materno-fetal: trombosis materna, restricción del crecimiento fetal (RCF), abortos recurrentes, complicaciones fetales, entre otros.

La importancia en el conocimiento de esta patología radica en la posibilidad de prevención de las complicaciones con los tratamientos disponibles.

Aún hay puntos controversiales y dificultades con respecto al SAF Obstétrico. Es difícil definir la relación causa-efecto dada la patogenia multifactorial que presenta. Se plantea que algunos efectos en relación con los factores de la coagulación (factores protrombóticos), los efectos contra la Anexina $\mathrm{V}$ y activación del complemento actúan como factores etiológicos en la falla de implantación y pérdida recurrente de embarazo (PRE), sin embargo la determinación de muchos de estos factores no están integrados en la práctica clínica habitual. Se discute también el potencial trombogénico de los diferentes anticuerpos en relación a la clínica así como la presencia de anticuerpos antifosfolipídicos (AAF) en mujeres sanas. Por otra parte siempre deben excluirse otras causas de mala historia obstétrica en relación a mal control de enfermedades co-existentes como hipertensión arterial (HTA), enfermedad renal crónica, LES, diabetes e hipotioridismo, entre otras.

Los criterios incluidos como resultados adversos del embarazo potencialmente relacionado al SAF se han definido de diferentes formas por los distintos investigadores, esto ha contribuido a resultados conflictivos en los diferentes estudios. Con la intención de solucionar este problema en 2006 la sociedad internacional de hemostasis y trombosis propone los criterios que definen las morbilidades del embarazo vinculadas al SAF que se enumeran a continuación:

1) Pérdida fetal tardía (PFT): $\geq 1$ muerte fetal inexplicada $\geq 10$ semanas de gestación, con morfología normal por ecografía prenatal o examen directo post-natal. La asociación entre pérdida fetal tardía y SAF se fundamenta en gran parte por estudios retrospectivos. En algunos estudios de pérdida fetal mayor a 10 semanas, ocurre con mayor proporción en mujeres con AAF que en mujeres $\sin \mathrm{AAF}$ (50 \% versus $15 \%$ respectivamente) ${ }^{3}$. Además, más del $80 \%$ de las mujeres con AAF tenían al menos una muerte fetal, comparado con menos del $25 \%$ de las mujeres sin AAF $(p<001)$. Existe además una correlación entre los niveles de Ac anticardiolipina (aCL) lgG y el riesgo de pérdida fetal ${ }^{4}$. Como hemos mencionado previamente, la mayoría de los pacientes con SAF secundarios están vinculados a enfermedades autoinmunes (en su mayoría secundario a LES). Sin embargo, el riesgo de pérdida fetal parece ser independiente, al menos en parte de la enfermedad autoinmune subyacente. En una revisión de 10 estudios que incluyen 554 mujeres con LES, la pérdida fetal era más común en aquellos con AAF (38 a 59\% con AAF versus 16 a $20 \%$ sin AAF), en aquellas con inhibidor lúpico (IL) (36\% con IL versus $13 \%$ sin IL) y con aCL $(39 \% \text { con aCL versus } 18 \% \sin \mathrm{aCL})^{5}$.

2) Pérdida recurrente de embarazo (PRE): $\geq 3$ pérdidas de embarazos < a 10 semanas de gestación, consecutivas no explicadas por causas anatómicas, hormonales o alteraciones cromosómicas maternas o paternas. La asociación entre pérdida recurrente de embarazo y SAF se basa en su gran mayoría en estudios descriptivos. La mayoría reportan consistentemente que los AAF se detectan en una alta proporción de mujeres con PRE en comparación con los controles (mayor a $20 \%$ versus menor del $5 \%)^{6-14}$. Uno de estos estudios, tenía como objetivo determinar la prevalencia del IL y aCL en mujeres con historia de pérdida de embarazo en el primer trimestre. De 243 pacientes $47 \%$ tenían historia de 2 abortos y $53 \%$ tenían historia de 3 o más abortos. De las 243 mujeres investigadas, $16.8 \%$ tenían resultados patológicos de IL y aCL. En mujeres con historia de 2 abortos, $15 \%$ tenían valores patológicos de aCL o IL; comparados con $18.5 \%$ de aquellas con 3 o más abortos (no habían diferencias significativas) ${ }^{12}$. En el estudio de casos y control de Parazzini que evalúa la asociación entre $\mathrm{aCL}$, IL y el riesgo de recurrencia de abortos espontáneo. De 220 mujeres con dos o más abortos espontáneos consecutivos y 193 controles, IL era detectado en 16 de 220 casos (7\% IC 95\% entre 4-11\%) pero en ninguno de los controles ${ }^{13}$. Niveles mayores de aCL eran demostrados en 19 de 99 casos (19\% IC 95\% entre 12-31\%) y 4 pacientes en los controles (3\%). Debe tenerse en cuenta que muchos de los estudios citados no tenían como referencia los niveles de anticuerpos tomados como positivos actualmente (véase: criterios de laboratorio). 
3) Parto pretérmino: $\geq 1$ parto pretérmino antes de las 34 semanas, con recién nacido morfológicamente normal, secundario a preeclampsia (Pre-E) severa, eclampsia o características consistentes con insuficiencia placentaria. Se aceptan como insuficiencia placentaria: a) test anormal de valoración de vitalidad fetal (ejemplo NST) sugestivos de hipoxia fetal; b) Doppler placentario anormal (por ejemplo ausencia de flujo diastólico en arteria umbilical) sugestivos de hipoxia fetal, c) oligohidramnios; d) Recién nacido con peso menor al percentil 10 para la edad gestacional, o restricción del crecimiento fetal. Dos revisiones sistemáticas han reportado asociación significativa entre el desarrollo de preeclampsia y aCL y posiblemente $\mathrm{IL}^{15,16}$. En una de las revisiones se incluyeron 12 estudios en el metanalisis; el OR para asociación de aCL con preeclampsia era 2.86 (IC 95\% 1.37-5.98) mientras que el OR de aCL con preeclampsia severa era de 11.15 (IC 95\% 2.66-46.75). Se concluye en dicho estudio que niveles moderados a altamente elevados de $\mathrm{aCL}$ se asocia con preeclampsia16. En la segunda revisión sistemática, el OR para aCL era de 2,73 (IC 95\% 1.65-4.51) y para IL 1.45 (IC 95\% 0.70-4.61) $)^{15}$. Entre los pacientes con SAF, la frecuencia de RCF era del $30 \%$ que era significativamente más alto que en la población general (tasa de RCF en la población general: 10\%) ${ }^{17}$.

4) Enfermedad tromboembólica: Durante el embarazo y el puerperio existe un aumento del riesgo de enfermedad tromboembólica y este riesgo es aún más alto en pacientes con SAF. En estudios prospectivos el riesgo de ETEV durante el embarazo y puerperio era de $12 \%$ al $5 \%$ entre mujeres con SAF conocido (comparado con 0,025 a 0,10\% en la población obstétrica general) $)^{17,18}$. La trombosis venosa es más frecuente que la trombosis arterial. En consecuencia, las mujeres con trombosis asociada a SAF puede tener altas tasas complicaciones en el embarazo y complicaciones fetales que aquellas que sólo tiene complicaciones obstétricas asociadas a SAF ${ }^{19,20}$.

\section{¿Cuándo debemos solicitar los AAF?}

Deben solicitarse los AAF en mujeres con historia de trombosis arterial o venosa inexplicada y nueva trombosis arterial o venosa durante el embarazo.

Las indicaciones obstétricas para valorar la presencia de AAF incluyen historia de una pérdida fetal tardía y PRE ${ }^{21}$. Aunque el comité de expertos (Practice Bulletin The American College of Obstetricians and Gynecologists, 2012) hace referencia a que el parto pretérmino por pre eclampsia e insuficiencia placentaria son criterios clínicos de SAF; actualmente existen datos insuficientes para recomendar el screening en mujeres con estas condiciones dado la pobre evidencia de que los tratamiento actualmente disponibles para estas condiciones mejoren los resultados obstétricos. Esta recomendación es controversial dado que algunos autores aconsejan solicitar los AAF en estas condiciones. Otras manifestaciones asociadas al SAF, como anemia hemolítica, trombocitopenia inmune, amaurosis fugaz, livedo reticularis y LES no son consideradas criterios diagnóstico de SAF por lo que la solicitud de los AAF debe individualizarse y no se aconseja su pedido en la presencia aislada de estas condiciones ${ }^{22}$. La solicitud de AAF en pacientes con manifestaciones no vinculadas claramente a SAF puede llevar a situaciones de difícil interpretación y manejo.

\section{Definición de SAF Obstétrico}

Se define SAF Obstétrico según los criterios de Sapporo 1999 y revisados en Sydney 2006 (Miyakis et al), debiendo estar presente 1 criterio clínico más 1 de laboratorio ${ }^{2,23}$.

Criterios clínicos: Uno o más episodios de trombosis venosa, arterial y/o de pequeño vaso (imagen o evidencia histológica) en cualquier órgano o tejido y/o morbilidad del embarazo: una o más muertes fetales > 10 semanas de feto morfológicamente normal; uno o más pretérminos < 34 semanas secundario a Pre-E severa o Eclampsia (de acuerdo a la definición estándar) o insuficiencia placentaria (RCF <menor a percentil 10 por ecografía), oligohidramnios, hipoxemia fetal sugeridos por ecografía doppler o nonstress Test (NST), de fetos morfológicamente normales; tres o más abortos espontáneos consecutivos inexplicados < de 10 semanas (excluidas otras causas: cromosómicas maternas o paternas, y anatómicas o endocrinas maternas).

Criterios de laboratorio: presencia de AAF en dos o más ocasiones, con una diferencia de 12 semanas como mínimo, según criterios de la Sociedad Internacional de Trombosis y Hemostasis (ISTH): ACA isotipos IgG o IgM > de 40U GPL o MPL o > de percentil 99. Anti B2 GPI (anti beta 2 glicoproteína I) lgG o IgM > percentil 99. IL positivo. 
El punto de corte y el requisito de dos o más determinaciones es importante para descartar falsos positivos, los cuales pueden ser a bajo título y transitorios vinculados a fármacos e infecciones entre otras causas. No es necesario realizar estudio confirmatorio a las 12 semanas en caso de ser negativos. El estudio de otros anticuerpos que pueden estar presentes en el SAF pero su incidencia es menos frecuentes y de dudosa sensibilidad y especificidad (anti Anexina $\mathrm{V}$, anti fosfatidilinositol y anti protrombina) aún no han sido avalados, si bien están en desarrollo importantes estudios de investigación ${ }^{24}$.

\section{Tratamiento}

El objetivo terapéutico es prevenir complicaciones (morbi-mortalidad) materno-fetal (trombosis maternas y prevenir complicaciones obstétricas). El tratamiento siempre debe ser individualizado según cada caso particular.

A los efectos prácticos, parece lógico razonar cada paciente según las siguientes consideraciones: aquellas pacientes con historia previa de eventos trombóticos y las pacientes sin historia de trombosis previa o actual.

\section{a) SAF trombótico (criterio de laboratorio asociado a trombosis previa)}

En este caso en general son pacientes que vienen recibiendo anticoagulación oral (ACO) previo al embarazo. Según las guías del ACCP $2012^{21}$, se sugiere anticoagulación con heparinas de bajo peso molecular (HBPM) a dosis ajustadas al peso materno del inicio del embarazo (o dosis terapéuticas). Las mujeres que reciben ACO deben recibir consejo sobre el potencial riesgo teratogénico de la warfarina, por lo tanto las mujeres con warfarina o anticoagulantes orales de acción directa deben planificarse el cambio a HBPM durante el período de la concepción o una vez quede embarazada antes de las 6 semanas de edad gestacional. La warfarina puede reiniciarse en el postparto.

Se recomienda además asociar dosis bajas de Ácido acetilsalicílico (AAS) (80-100 mg día) a los efectos de disminuir el riesgo de Pre-E desde la semana 12 hasta el parto.

\section{b) SAF trombótico (criterio de laboratorio asociado a trombosis aguda/actual)}

Para las pacientes que desarrollan una trombosis durante el embarazo y presenta AAF positivos, según los criterios diagnósticos referidos previamente, debe iniciarse HBPM a dosis ajustadas asociada a AAS a dosis bajas. En cuanto a la anticoagulación se recomienda continuar al menos 6 semanas post parto y como mínimo 3 meses desde el evento trombótico ${ }^{21}$. Debe valorarse en cada caso anticoagulación en forma indefinida para las pacientes que cumplen los criterios de SAF. Las consideraciones del uso de warfarina en el post parto son las mismas que en el punto anterior. La AAS se mantiene hasta el parto. En otras revisiones se aborda el tratamiento de la enfermedad tromboembólica venosa en el período grávido-puerperal.

\section{c) SAF obstétrico por pérdida fetal tardía o PRE}

Se sugiere la combinación de dosis bajas de AAS (80 a 100 mg día) comenzando desde la concepción, y dosis profilácticas de heparina luego de confirmar el embarazo intrauterino. El AAS se mantiene hasta el parto y la HBPM hasta 6 semanas del puerperio para prevención de trombosis materna.

Un metanálisis publicado que incluyó 10 estudios (627 pacientes) que tenían como objetivo valorar los resultados terapéuticos en relación a la PRE y SAF; evidenció que en tres estudios el uso de AAS sola no mostraba una reducción significativa de la pérdida de embarazo (RR 1.05, IC $95 \% 0.66$ y 1.68). El uso de heparina combinada con AAS (dos estudios, 140 pacientes) reducía significativamente la pérdida de embarazo (RR 0.46 IC 95\% 0.29-0.71) mientras que el uso de AAS y prednisona resulta en un importante incremento de la prematurez (RR 4.83, IC 2.85-8.21) sin una reducción significativa en la reducción de la pérdida de embarazo (RR 0.85 , IC $95 \%$ 0.53.1.36 $)^{25}$.

En este estudio se concluye que las pacientes con PRE y anticuerpos antifosfolipidos el uso de heparina y AAS puede reducir la pérdida de embarazo en un $54 \%{ }^{25}$. Se ha reportado que en pacientes con pérdida de embarazo en el $1^{\circ}$ trimestre, el uso de heparina y AAS puede reducir el riesgo (OR 0.39, IC 95\% 0.24-0.65) e incrementar el número de recién nacidos vivos (RR 1.3, IC 1.04-1.63 $)^{26,27}$. Sin embargo, se debe tener en cuenta varias limitaciones de los estudios, muchos con un número pequeño de pacientes, los tratamientos no eran aleatorizados adecuadamente e incluso los resultados de pacientes que salieron del estudio, y que presentaron efectos adversos no estaban disponibles. 


\section{d) SAF obstétrico por parto pretérmino, debido a insuficiencia placentaria}

Se sugiere dosis bajas de AAS (80 a $100 \mathrm{mg}$ día) e iniciando a las 12 y a las 28 semanas y continuar hasta el parto ${ }^{21,22}$. Algunos autores recomiendan profilaxis con heparina y AAS en caso de fallas con AAS para pacientes que muestran a nivel placentario inflamación decidual, vasculopatía o trombosis, aunque esta recomendación no se basa en ensayos clínicos controlados.

\section{e) Mujeres con AAF sin criterio clínico de SAF}

Hay pocos datos que guíen el manejo de las embarazadas sin complicaciones con la presencia de AAF aislados y que por lo tanto no cumplen los criterios de SAF antes mencionados. Más del $50 \%$ de tales mujeres tienen embarazos sin complicaciones sin mediar ningún tratamiento farmacológico ${ }^{28,29}$. Las opciones terapéuticas incluyen: no tratamiento farmacológico, AAS a dosis bajas, heparina profiláctica y AAS a dosis bajas. Algunos autores están a favor de AAS a dosis bajas únicamente, sin embargo en 2015 se publica una revisión sistemática de 154 embarazadas en las que se utilizaba profilaxis primaria para prevenir complicaciones obstétricas de mujeres asintomáticas con ACA en la que no encontró beneficios del uso de $\operatorname{AAS}^{30,31}$.

\section{Otros tratamientos}

Aproximadamente un 20 a $30 \%$ de las pacientes tratadas con el tratamiento estándar (HBPM+ AAS) presentan complicaciones obstétricas. El tratamiento de este grupo de pacientes, refractarias al tratamiento estándar es objeto de debate ${ }^{32}$.

Se ha ensayado el uso de Hidroxicloroquina (HCQ), con resultados interesantes, aunque aún no concluyentes. HCQ tiene efecto antitrombótico y anti-inflamatorio, su uso es eficaz y seguro durante el embarazo de pacientes con LES, tanto para la madre como para el feto. El tratamiento con HCQ puede ofrecer también una protección adicional frente a las pérdidas fetales, dado su efecto protector sobre la anexina $\mathrm{V}$ placentaria, imprescindible para evitar las trombosis a dicho nivel. Más allá de reportes de casos exitosamente tratados con $\mathrm{HCQ}$, en donde había fallado el tratamiento con HBPM + AAS se están llevando a cabo estudios prospectivos. El estudio multicéntrico "Hypatia", en curso, incluyó pacientes con AAF. Los pacientes fueron tratados con el tratamiento estándar más HCQ. Es de destacar que no se trata de pacientes en los cuales haya fallado el tratamiento estándar ni de alto riesgo (triple positivos o positivos para inhibidor lúpico). Por su parte, existen series retrospectivas en las cuales el tratamiento con HCQ 400 mg, mostró beneficios adicionales al tratamiento estándar de HBPM + AAS. Si bien existen estudios en curso, aún no hay evidencia concluyente para recomendar su uso en casos de refractariedad de SAF obstétrico. Sin embargo, dada la seguridad del medicamento, podría considerarse su uso en casos de refractariedad ${ }^{33-36}$.

También se han reportado beneficios con el uso de Pravastatina, una estatina hidrosoluble con prácticamente nula transferencia placentaria, en pacientes con historia de insuficiencia placentaria $^{37}$.

Una publicación del grupo del St. Thomas' Hospital exploró el uso de prednisona en dosis no superiores a $10 \mathrm{mg} /$ día, desde el diagnóstico del embarazo hasta la semana 14 de la gestación, en combinación con Aspirina y HBPM en pacientes con SAF obstétrico que habían tenido malos resultados obstétricos con terapia estándar. La tasa de pérdida fetal cayó de $30 \%$ a $9 \%$, resultando en $60 \%$ de recién nacidos vivos y en una mejoría de los resultados obstétricos en estas pacientes. Si bien estos resultados son interesantes, no son concluyentes para establecer una recomendación de uso, más aun teniendo en cuenta su conocido perfil de efectos adversos ${ }^{38}$.

Por último, el uso de Inmunoglobulina se ha probado en el SAF obstétrico refractario, pero hoy en día no existe evidencia que avale su uso con un razonable perfil de eficacia y seguridad ${ }^{39}$. 


\section{Recomendaciones}

En la tabla 1 se presentan las recomendaciones.

\begin{tabular}{|l|l|}
\hline \multicolumn{1}{|c|}{ Situación clínica } & \multicolumn{1}{|c|}{ Conducta en embarazo y puerperio } \\
\hline Antecedente de trombosis & $\begin{array}{l}\text { Profilaxis con dosis ajustada de Heparina (HBPM) más AAS } 100 \\
\text { mg (2C), en embarazo, y puerperio por un mínimo de } 6 \text { semanas. } \\
\text { Considerar a largo plazo (Warfarina). }\end{array}$ \\
\hline Antecedente de $\geq 1$ aborto tardío ( $\geq$ a 10 semanas) & $\begin{array}{l}\text { HBPM a dosis profiláctica o intermedia en embarazo y puerperio. } \\
\text { Asociado AAS 100mg/día. (2B) }\end{array}$ \\
\hline $\begin{array}{l}\text { Antecedente de PRE (más } 203 \text { AE menores a 10 } \\
\text { semanas) sin trombosis previa. }\end{array}$ & $\begin{array}{l}\text { HBPM profiláctica más AAS en embarazo (2B). Profilaxis en } \\
\text { puerperio por } 6 \text { semanas mínimo. }\end{array}$ \\
\hline $\begin{array}{l}\text { Antecedente de pré términos menor de 34 } \\
\text { semanas por Pré-E severa /Eclâmpsia o RCF. }\end{array}$ & AAS (2C) o AAS más HBPM en embarazo, y puerperio. \\
\hline AAF sin criterios clínicos de SAF & $\begin{array}{l}\text { Control. } \\
\text { Valorar según caso particular en base a criterio clínico: AAS o AAS } \\
\text { más HBPM. Se sugiere AAS sobre no tratamiento. (2C) }\end{array}$ \\
\hline
\end{tabular}

Las manifestaciones obstétricas vinculadas al SAF se definen como:

1) $\geq 1$ muerte fetal mayor a 10 semanas de gestación con feto morfológicamente normal, con ultrasonido prenatal o examen morfológico postnatal.

2) $\geq 1$ parto pretérmino de un recién nacido normal antes de las 34 semanas debido a Pre-E severa, eclampsia o hallazgos consistentes con insuficiencia placentaria.

3) $\geq 3$ pérdidas fetales menores a 10 semanas de gestación, espontáneas y consecutivas, luego de excluir causas anatómicas, hormonales o cromosómicas.

1-SAF trombótico, dado por criterios de laboratorio e historia de trombosis arterial o venosa, tienen riesgo de recurrencia por lo que habitualmente son tratadas con warfarina en forma indefinida, por lo que deben recibir HBPM a dosis de anticoagulación durante la gestación y reiniciar la warfarina en el posparto (grado de evidencia $2 \mathrm{C}$ ).

2-SAF Obstétrico, dado por mala historia obstétrica y laboratorio positivo, se recomienda el uso de HBPM y AAS a dosis bajas sobre HBPM sólo (grado de evidencia 2B). En caso de Pérdida fetal tardía o PRE se sugiere dosis bajas de AAS (50 a 100mg día) y dosis profilácticas de HMBP, sobre AAS sólo (grado de evidencia 2B) y continuar este régimen por 6 semanas postparto. En caso de mujeres con $\geq 1$ parto pretérmino de un recién nacido normal antes de las 34 semanas, debido a preeclampsia severa, eclampsia o hallazgos consistentes con insuficiencia placentaria se sugiere dosis bajas de AAS. (grado de evidencia 2C). Algunos autores realizan AAS y HBPM en casos de fallo de AAS y en situaciones en que el examen placentario muestre extensa inflamación decidual o vasculopatía o trombosis sin embargo esta conducta no se ha validado mediante ensayos clínicos.

3-Hallazgo incidental de AAF, que no cumplen criterios de SAF, algunos autores sugieren dosis bajas de AAS sobre no tratamiento (grado de evidencia $2 \mathrm{C}$ ).

\section{Situaciones clínicas particulares}

\section{a) Fertilización in vitro en pacientes con AAF sin criterios clínicos de SAF}

No existe evidencia de buena calidad que sugiera que las pacientes con AAF sin criterios de SAF/SAF obstétrico que van a ser sometidas a fertilización in viro (FIV) se beneficien de realizar terapia profiláctica ${ }^{40}$.

Sin embargo, algunos estudios han encontrado un riesgo aumentado de enfermedad tromboembólica venosa (ETEV) durante el primer trimestre en pacientes que se realizaron FIV. Un estudio publicado en el 2013 evidencia un riesgo de embolia pulmonar en primer trimestre (en pacientes con AAF negativos y sin síndrome de hiperestimulación ovárica) 3 cada 10000 vs 0,4 cada 10000 (HR 6.97, 95\% Cl 2.21 - 21.96) de las que se embarazaron en forma espontánea ${ }^{41}$. 
Dada que la evidencia es de baja calidad y conflictiva, la decisión de realizar tromboprofilaxis durante el período de estimulación debe estar basada en el riesgo individual de cada paciente.

En el grupo de pacientes AAF positivos sin criterio clínico de SAF, las opciones terapéuticas durante el embarazo deben considerarse también en forma individual.

Las opciones terapéuticas más utilizadas van desde no tratamiento, tratamiento con AAS 100 mg o AAS 100 mg más HBPM a dosis de tromboprofilaxis. La presencia de AAF por sí solos, no parece afectar negativamente la tasa de éxito de la FIV42,43.

\section{b) Fertilización in vitro en pacientes con SAF}

La experiencia en este grupo es extremadamente limitada. La FIV es potencialmente riesgosa en estas pacientes ya que los regímenes de inducción de la ovulación desencadenan un estado protrombótico inducido por estrógenos. En las mujeres con SAF asociado a trombosis previa, se recomienda pasar de su anticoagulante oral habitual a una dosis terapéutica de HBPM que debe mantenerse hasta después de la recuperación de ovocitos. Si no se logra el embarazo, se sugiere mantener la HBPM a través de ciclos repetidos de FIV o volver a anticoagulación oral (en caso de recibirlos) o suspender la anticoagulación si no se planean más ciclos.

La mayoría de las complicaciones trombóticas observadas ocurrieron en ciclos que incluían agonistas $\mathrm{GnRH}$ para inducir la ovulación. La utilización de protocolos que incluyan antagonistas $\mathrm{GnRH}$ o ciclos naturales disminuye los riesgos de trombosis ${ }^{44}$.

\section{c) SAF catastrófico obstétrico}

El Síndrome antifosfolipídico catastrófico (en adelante CAPS, por su sigla en inglés) es una variante del SAF, de mayor gravedad y rápida progresión. La descripción inicial fue realizada por Asherson et al. hace ya más de 20 años. Se caracteriza por la presencia de una serie de fenómenos tromboembólicos sucesivos (tres o más) graves, separados por un breve período de tiempo, comprometiendo característicamente la microvasculatura.

En el año 2003 se establecieron los criterios clasificatorios preliminares, ratificados en 2104 , cuya vigencia se mantiene hasta hoy (Tabla 2), definiendo dos grupos de pacientes, aquellos que cumplen la totalidad de los criterios, que son clasificados como CAPS "definido" y aquellos que no cumplen la totalidad, que son clasificados como CAPS "probable". Nótese que se trata de criterios clasificatorios, cuya presencia puede no coincidir con la gravedad del paciente. Por lo tanto, como suele ocurrir, los criterios clasificatorios no sustituyen al criterio clínico ${ }^{45}$.

a) Compromiso vaso-oclusivo (arterial o venoso) de tres o más órganos, sistemas o tejidos. Esto puede ser observado por estudios de imagen y, a nivel renal por: aumento de la creatinina plasmática > 50\%, hipertensión > 180/100 mmHg y/0 proteinuria $>500 \mathrm{mg} / 24$ horas

b) Las manifestaciones vasooclusivas se desarrollan de manera simultánea 0 en el plazo de 1 semana

c) Confirmación histopatológica de trombosis en al menos un órgano o tejido

d) Presencia de anticuerpos antifosfolípidos (inhibidor lúpico, anticuerpos anticardiolipina). Si es el debut se establece que deben persistir positivos en un plazo de 6 semanas.

CAPS definido: presencia de los cuatro criterios.

CAPS probable: los cuatro criterios, pero sólo dos parénquimas comprometidos.

Los cuatro criterios, anticuerpos presentes pero imposibilidad de confirmarlos a las 6 semanas por fallecimiento del paciente

Tabla 2: Criterios clasificatorios para

Criterios a), c) y d) pero desarrollo de los tres eventos trombo-embólicos en plazo mayor a una semana, pero menor a un mes.

De acuerdo con datos del "CAPS registry", $70 \%$ de los casos ocurre en pacientes de sexo femenino y la media de edad de ocurrencia es 38 años. El CAPS ocurre en el $1 \%$ de los pacientes con SAF, siendo el embarazo un factor desencadenante identificado en $8 \%$ de los casos. Puede ocurrir en pacientes con SAF conocido, pero se ha estimado que puede debutar en el embarazo hasta en la mitad de los casos. Otros desencadenantes descritos son las infecciones graves, las cirugías mayores, el cáncer y el uso de anticonceptivos. Más de la mitad de los casos son primarios, $1 / 3$ están relacionados con Lupus Eritematoso Sistémico y un 15\% de los pacientes presentan este cuadro grave como primera manifestación del $\mathrm{SAF}^{46}$.

Además de la presencia de fenómenos trombóticos y AAF, se destaca que dos tercios de los casos presentan trombocitopenia y la presencia de anticuerpos anti-DNA es relativamente 
frecuente (hasta $1 / 3$ de los casos). De igual modo, pueden observarse esquistocitos, enzimas hepáticas y creatinina elevada, proteinuria y hematuria. Estos hallazgos obligan a descartar otros cuadros clínicos asociados con el embarazo, todos ellos pasibles de presentarse con trombocitopenia y anemia hemolítica microangiopática, como síndrome de Pre-E severa, síndrome urémico-hemolítico, síndrome HELLP, púrpura trombocitopénico trombótico, hígado agudo graso del embarazo ${ }^{47}$.

El tratamiento del CAPS está basado en evidencia débil, más aún para el caso del CAPS obstétrico. Se acepta que estas pacientes deben recibir una "triple terapia", con anticoagulantes a dosis terapéuticas, preferentemente heparina no fraccionada intravenosa; glucocorticoides (terapia en pulso con Metilprednisolona) e inmunoglobulinas $(0.4 \mathrm{~g} / \mathrm{kg} /$ día por 3 a 5 días $)$ o plasmaféresis (2-3 litros/día por 3 a 5 días). Además, dada la gravedad del cuadro, las pacientes requerirán tratamiento de soporte de las funciones vitales. Conceptualmente debe tratarse el agente desencadenante, si se identifica. En el caso de la gestación, la interrupción de la gestación debe plantearse en gestaciones mayores a 34 semanas. A menor edad gestacional puede plantearse esperar 24-48 horas la respuesta al tratamiento, controlando estrechamente la salud materna y fetal ${ }^{45,48}$.

Se han ensayado otros tratamientos para el CAPS, pero aún no se ha establecido su eficacia, menos aún durante la gestación. Tal es el caso de Hidroxicloroquina, Rituximab y Eculizumab ${ }^{48,49}$.

\section{Bibliografía}

1- Hughes GR, Harris NN, Gharavi AE. The anticardiolipin syndrome. J Rheumatol. 1986 Jun;13(3):486-9.

2- Miyakis S, Lockshin MD, Atsumi T, Branch DW, Brey RL, Cervera R, et al. International consensus statement on an update of the classification criteria for definite antiphospholipid syndrome (APS). J. Thromb. Haemost. 2006;4(2):295-306.

3- Oshiro BT, Silver RM, Scott JR, Yu H, Branch DW. Antiphospholipid antibodies and fetal death. Obstet. Gynecol. 1996;87(4):489-93.

4- Lynch A, Marlar R, Murphy J, Davila G, Santos M, Rutledge J, et al. Antiphospholipid antibodies in predicting adverse pregnancy outcome. A prospective study. Ann Intern Med. 1994 Mar 15;120(6):4705. doi: 10.7326/0003-4819-120-6-199403150-00004.

5- McNeil HP, Chesterman CN, Krilis SA. Immunology and clinical importance of antiphospholipid antibodies. Adv Immunol. 1991;49:193-280. doi: 10.1016/s0065-2776(08)60777-4.

6- Out HJ, Kooijman CD, Bruinse HW, Derksen RH. Histopathological findings in placentae from patients with intra-uterine fetal death and anti-phospholipid antibodies. Eur J Obstet Gynecol Reprod Biol. 1991 Oct 8;41(3):179-86. doi: 10.1016/0028-2243(91)90021-c.

7- Parke AL, Wilson D, Maier D. The Prevalence of Antiphospholipid Antibodies in Women With Recurrent Spontaneous Abortion, Women With Successful Pregnancies, and Women Who Have Never Been Pregnant. Arthritis Rheum. 1991;34(10):1231-1235.

8- Petri M, Golbus M, Anderson R, Whiting-O'Keefe Q, Corash L, Hellmann D. Antinuclear antibody, lupus anticoagulant, and anticardiolipin antibody in women with idiopathic habitual abortion. A controlled, prospective study of forty-four women. Arthritis Rheum. 1987 Jun;30(6):601-6. doi: 10.1002/ art.1780300601.

9- Rai RS, Regan L, Clifford K, Pickering W, Dave M, Mackie I, McNally T, et al. Immunology: Antiphospholipid antibodies and $\otimes 2$-glycoprotein-i in 500 women with recurrent miscarriage: Results of a comprehensive screening approach. Hum. Reprod. 1995;10(8):2001-2005.

10- Balasch J, Creus M, Fábregues F, Reverter JC, Carmona F, Tàssies D, et al. Antiphospholipid antibodies and human reproductive failure. Hum. Reprod. 1996;11(10):2310-2315.

11- Kutteh WH. Antiphospholipid antibody-associated recurrent pregnancy loss: Treatment with heparin and low-dose aspirin is superior to low-dose aspirin alone. Am. J. Obstet. Gynecol. 1996;174(5):15841589.

12- MacLean MA, Cumming GP, McCall F, Walker ID, Walker JJ. The prevalence of lupus anticoagulant and anticardiolipin antibodies in women with a history of first trimester miscarriages. BJOG An Int. J. Obstet. Gynaecol. 1994;101(2):103-106.

13- Parazzini F, Acaia B, Faden D, Lovotti M, Marelli G, Cortelazzo S. Antiphospholipid antibodies and recurrent abortion. Obstet Gynecol. 1991;77:854-8. 
14- Yetman DL, Kutteh WH. Antiphospholipid antibody panels and recurrent pregnancy loss: Prevalence of anticardiolipin antibodies compared with other antiphospholipid antibodies. Fertil. Steril. 1996;66(4):540-546.

15- Robertson L, Wu O, Langhorne P, Twaddle S, Clark P, Lowe GD, et al. Thrombophilia in pregnancy: a systematic review. Br. J. Haematol. 2006;132(2):171-96.

16- do Prado AD, Piovesan DM, Staub HL, Horta BL. Association of Anticardiolipin Antibodies. Obstet. Gynecol. 2010;116(6):1433-1443.

17- Branch DW, Silver RM, Blackwell JL, Reading JC, Scott JR. Outcome of treated pregnancies in women with antiphospholipid syndrome: an update of the Utah experience. Obstet. Gynecol. 1992;80(4):61420.

18- Lima F, Khamashta MA, Buchanan NM, Kerslake S, Hunt BJ, Hughes GR. A study of sixty pregnancies in patients with the antiphospholipid syndrome. Clin Exp Rheumatol. 1996 Mar-Apr;14(2):131-6

19- Bramham K, Hunt BJ, Germain S, Calatayud I, Khamashta M, Bewley S, Nelson-Piercy C. Pregnancy outcome in different clinical phenotypes of antiphospholipid syndrome. Lupus. 2010 Jan;19(1):58-64. doi: 10.1177/0961203309347794.

20- Yelnik CM, Lambert M, Drumez E, Le Guern V, Bacri JL, Guerra MM, et al. Bleeding complications and antithrombotic treatment in 264 pregnancies in antiphospholipid syndrome. Lupus. 2018;27(10):16791686.

21- Bates SM, Greer IA, Middeldorp S, Veenstra DL, Prabulos AM, Vandvik PO. VTE, thrombophilia, antithrombotic therapy, and pregnancy: Antithrombotic Therapy and Prevention of Thrombosis, 9th ed: American College of Chest Physicians Evidence-Based Clinical Practice Guidelines. Chest. 2012 Feb;141(2 Suppl):e691S-e736S. doi: 10.1378/chest.11-2300. PMID: 22315276.

22- Committee on Practice Bulletins-Obstetrics, American College of Obstetricians and Gynecologists. Practice Bulletin No. 132: Antiphospholipid syndrome. Obstet Gynecol. 2012 Dec;120(6):1514-21. doi: 10.1097/01.AOG.0000423816.39542.0f.

23- Wilson WA, Gharavi AE, Koike T, Lockshin MD, Branch DW, Piette JC, et al. International consensus statement on preliminary classification criteria for definite antiphospholipid syndrome: Report of an International Workshop. Arthritis Rheum. 1999;42(7):1309-1311.

24- Reber G, Tincani A, Sanmarco M, de Moerloose P, Boffa MC; Standardization group of the European Forum on Antiphospholipid Antibodies. Proposals for the measurement of anti-beta2-glycoprotein I antibodies. Standardization group of the European Forum on Antiphospholipid Antibodies. J Thromb Haemost. 2004 Oct;2(10):1860-2. doi: 10.1111/j.1538-7836.2004.00910.x.

25- Empson M, Lassere M, Craig JC, Scott JR. Recurrent pregnancy loss with antiphospholipid antibody: a systematic review of therapeutic trials. Obstet Gynecol. 2002 Jan;99(1):135-44. doi: 10.1016/s00297844(01)01646-5.

26- Ziakas PD, Pavlou M, Voulgarelis M. Heparin treatment in antiphospholipid syndrome with recurrent pregnancy loss: a systematic review and meta-analysis. Obstet Gynecol. 2010 Jun;115(6):1256-1262. doi: 10.1097/AOG.0b013e3181deba40.

27- Mak A, Cheung MW, Cheak AA, Ho RC. Combination of heparin and aspirin is superior to aspirin alone in enhancing live births in patients with recurrent pregnancy loss and positive anti-phospholipid antibodies: a meta-analysis of randomized controlled trials and meta-regression. Rheumatology (Oxford). 2010 Feb;49(2):281-8. doi: 10.1093/rheumatology/kep373.

28- Lockwood CJ, Romero R, Feinberg RF, Clyne LP, Coster B, Hobbins JC. The prevalence and biologic significance of lupus anticoagulant and anticardiolipin antibodies in a general obstetric population. Am J Obstet Gynecol. 1989 Aug;161(2):369-73. doi: 10.1016/0002-9378(89)90522-x.

29- Lockshin MD, Qamar T, Levy RA, Druzin ML. Pregnancy in systemic lupus erythematosus. Clin. Exp. Rheumatol. 7 Suppl 3:S195-7.

30- Tincani A, Branch W, Levy RA, Piette JC, Carp H, Rai RS, Khamashta M, et al. Treatment of pregnant patients with antiphospholipid syndrome. Lupus. 2003;12(7):524-9.

31- Amengual O, Fujita D, Ota E, Carmona L, Oku K, Sugiura-Ogasawara M, et al. Primary prophylaxis to prevent obstetric complications in asymptomatic women with antiphospholipid antibodies: a systematic review. Lupus. 2015;24(11):1135-42.

32- Mekinian A, Alijotas-Reig J, Carrat F, Costedoat-Chalumeau N, Ruffatti A, Lazzaroni MG, et al. Refractory obstetrical antiphospholipid syndrome: Features, treatment and outcome in a European multicenter retrospective study. Autoimmun. Rev. 2017;16(7):730-734. 
33- Schreiber K, Breen K, Cohen H, Jacobsen S, Middeldorp S, Pavord S, et al. HYdroxychloroquine to Improve Pregnancy Outcome in Women with AnTIphospholipid Antibodies (HYPATIA) Protocol: A Multinational Randomized Controlled Trial of Hydroxychloroquine versus Placebo in Addition to Standard Treatment in Pregnant Women with Antiphospholipid Syndrome or Antibodies. Semin. Thromb. Hemost. 2017;43(6):562-571.

34- De Carolis S, Botta A, Salvi S, di Pasquo E, Del Sordo G, Garufi C, et al. Is there any role for the hydroxychloroquine (HCQ) in refractory obstetrical antiphospholipid syndrome (APS) treatment? Autoimmun. Rev. 2015;14(9):760-762.

35- Ruffatti A, Tonello M, Hoxha A, Sciascia S, Cuadrado MJ, Latino JO, et al. Effect of Additional Treatments Combined with Conventional Therapies in Pregnant Patients with High-Risk Antiphospholipid Syndrome: A Multicentre Study. Thromb. Haemost. 2018;118(4):639-646.

36- Mekinian A, Lazzaroni MG, Kuzenko A, Alijotas-Reig J, Ruffatti A, Levy P, et al. The efficacy of hydroxychloroquine for obstetrical outcome in anti-phospholipid syndrome: Data from a European multicenter retrospective study. Autoimmun. Rev. 2015;14(6):498-502.

37- Lefkou E, Mamopoulos A, Dagklis T, Vosnakis C, Rousso D, Girardi G. Pravastatin improves pregnancy outcomes in obstetric antiphospholipid syndrome refractory to antithrombotic therapy. J. Clin. Invest. 2016;126(8):2933-2940.

38- Bramham K, Thomas M, Nelson-Piercy C, Khamashta M, Hunt BJ. First-trimester lowdose prednisolone in refractory antiphospholipid antibody - related pregnancy loss. Blood. 2011;117(25):6948-6951.

39- Ruffatti A, Favaro M, Hoxha A, Zambon A, Marson P, Del Ross T, Calligaro A, et al. Apheresis and intravenous immunoglobulins used in addition to conventional therapy to treat high-risk pregnant antiphospholipid antibody syndrome patients. A prospective study. J. Reprod. Immunol. 2016;115:1419.

40- Hornstein MD, Davis OK, Massey JB, Paulson RJ, Collins JA. Antiphospholipid antibodies and in vitro fertilization success: A meta-analysis. Fertil. Steril. 2000;73(2):330-333.

41- Henriksson P, Westerlund E, Wallén H, Brandt L, Hovatta O, Ekbom A. Incidence of pulmonary and venous thromboembolism in pregnancies after in vitro fertilisation: cross sectional study. BMJ. 2013;346(7892):e8632

42- Chilcott IT, Margara R, Cohen H, Rai R, Skull J, Pickering W, Regan L. Pregnancy outcome is not affected by antiphospholipid antibody status in women referred for in vitro fertilization. Fertil. Steril. 2000;73(3):526-30.

43- Derksen RHWM, Khamashta MA, Branch DW. Management of the obstetric antiphospholipid syndrome. Arthritis Rheum. 2004;50(4):1028-39.

44- Orquevaux P, Masseau A, Le Guern V, Gayet V, Vauthier D, Guettrot-Imbert G, et al. In vitro fertilization in 37 women with systemic lupus erythematosus or antiphospholipid syndrome: A series of 97 procedures. J. Rheumatol. 2017;44(5):613-618.

45- Ortel TL, Erkan D, Kitchens CS. How I treat catastrophic thrombotic syndromes. Blood. 2015;126(11):1285-1293.

46- Rodríguez-Pintó I, Moitinho M, Santacreu I, Shoenfeld Y, Erkan D, Espinosa G, et al. Catastrophic antiphospholipid syndrome (CAPS): Descriptive analysis of 500 patients from the International CAPS Registry. Autoimmun. Rev. 2016;15(12):1120-1124.

47- Silver RM. Catastrophic antiphospholipid syndrome and pregnancy. Semin. Perinatol. 2018;42(1):2632.

48- Makatsariya AD, Khizroeva J, Bitsadze VO. Catastrophic antiphospholipid syndrome (Ronald Asherson syndrome) and obstetric pathology. J. Perinat. Med. 2018;46(4):387-400.

49- Cervera R, Rodríguez-Pintó I, Espinosa G. The diagnosis and clinical management of the catastrophic antiphospholipid syndrome: A comprehensive review. J. Autoimmun. 2018;92:1-11.

\section{Aporte de cada autor al trabajo}

Daniel Leal: Concepción y diseño del trabajo, recolección de datos, redacción y revisión crítica del manuscrito.

Valentina Zubiaurre: Concepción y diseño del trabajo, recolección de datos, redacción y revisión crítica del manuscrito.

Alvaro Danza: Concepción y diseño del trabajo, recolección de datos, redacción y revisión crítica del manuscrito. 
Mariana Stevenazzi: Concepción y diseño del trabajo, recolección de datos, redacción y revisión crítica del manuscrito. 